\title{
2.2. QUALITY AND MANAGEMENT - TOOLS FOR CONTINUOUS AND SYSTEMATIC IMPROVEMENT OF PROCESSES
}

\begin{abstract}
Summary
Nowadays, the quality of the company is one of the essential part of the business competitiveness. The realization of quality is drastically changed in the last century. The level of development is depends on the point of view of direction, the possibilities of the organization, the external environment, the age and of the company. Business has also changed radically since the last major revision of ISO 9001 in 2000, as technology development has made substantial changes in working processes. In addition, geographical boundaries are almost insignificant in today's global economy, supply chains are increasingly complex and the information availability has multiplied exponentially. These changes affect the quality control processes and methods. Quality Management Systems shall adopt the changes to follow the requirements of customers and organizations and take the necessary evolutional steps from quality control to the Total Quality Management (TQM). In order to be realized as a management tool, quality principles shall be applied in all levels of operation, and for being successful, businesses have to adapt to the growing needs of customers.
\end{abstract}

Keywords: quality, management systems, TQM, ISO, costs of quality, role of managers

\section{Introduction - definitions of quality}

Nowadays, the quality of the company is an essential factor of business competitiveness. There is a long way taken from F. W. Taylor (1911) when he issued his book "The principles of Scientific Management". Quality takes the necessary evolutionary steps from quality control to the TQM (Total Quality Management). The in-between steps are known as quality control, quality assurance, quality systems and finally, the TQM.

It is very important to check, where is the point from which we can distinguish the difference between organizations: which will be successful and which will not? Some organizations just hang the certification on the wall, while another operates a successful quality system which will bring benefits for the whole company.

There are no general 'recipes' for a success, the correct steps should be established and carried out by leadership and management issues 'on the spot'. The problem is that there are not general measurement methods that could measure the performance of the management. In many companies several developments or projects (e.g. introduction of ISO system, TQM, etc.) are running simultaneously. The benefits of these activities sometimes can hardly be realized, because the introduction of ISO system will require high investment costs, and hardly predictable benefits. As Juran said, senior leaders speak the language of money; workers speak the language of things (machines, tools and products), and middle managers should be able to translate the language of money into language of things and vice versa for the successful performance of organizations (Juran, 1964; Defeo and Juran, 2014). According to Deming (2000), quality is mostly 
connected to the performance of the leaders and top managers, and workers are only responsible for their failures at the production line. Feigenbaum $(2004,2009)$ insisted on that quality should be discussed as a whole, and introduced his Total Quality Control system.

Total quality management is rather a philosophy or leadership attitude, which can be summarized as a management system for a customer-focused organization that involves all employees in continual improvement. It uses strategy, data, and effective communications to integrate the quality discipline into the culture and activities of the organization. The main principles of total quality management are summarized by Figure 1.

Figure 1: Principles of TQM

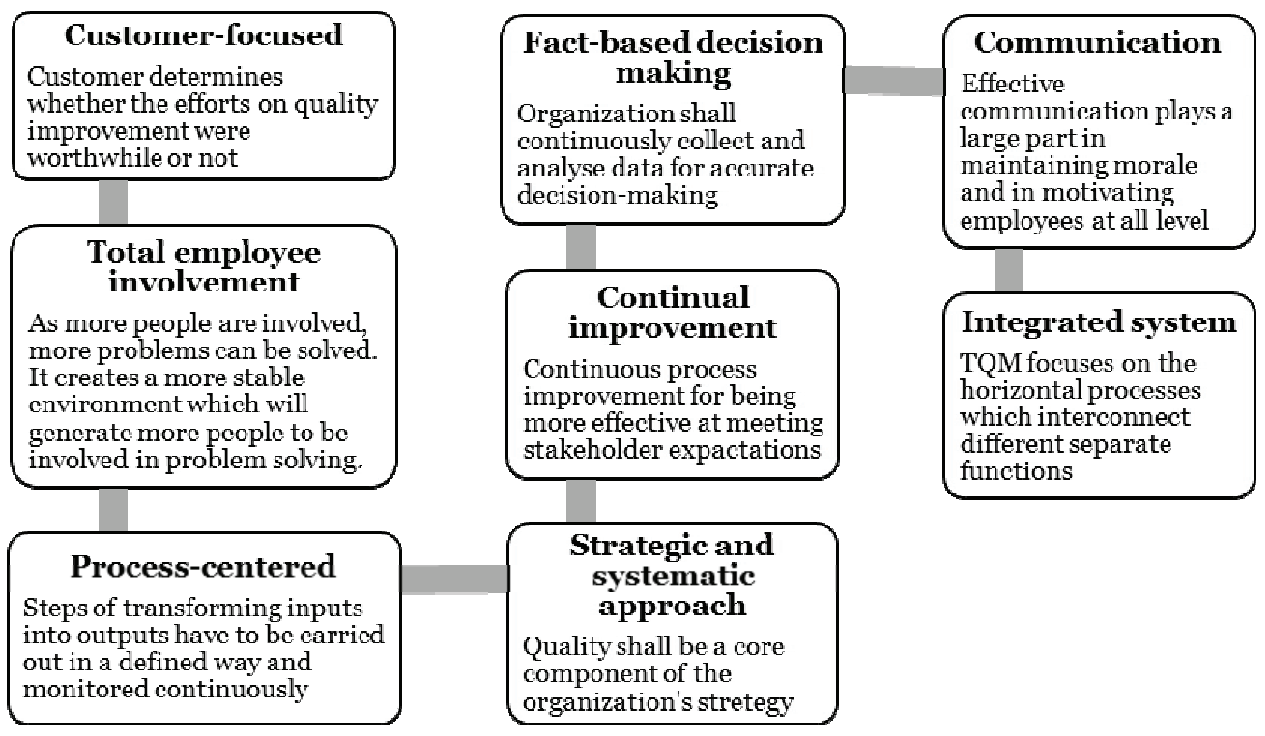

Source: own summary based on Oakland (2014) and Illés and Szuda (2015)

In manufacturing industry, quality traditionally means the continuous inspection especially in companies with Asian origin, but for the real success the company have to move towards operating really efficient quality management tools, which is affect the competitiveness of the company (IATF, 2014).

\section{Costs of quality}

When we define the meaning of quality, we shall state that it is a subjective term, for which each person or sector has its own definition. In technical usage, quality can have two meanings: the first means that he characteristics of a product or service that bear on its ability to satisfy stated or implied needs; the second meaning refers to that a product or service free of deficiencies.

According to Philip Crosby (1979), quality means "conformance to requirements". Quality is related not only to the quality of product, but it means the quality of 
operations, which covers the whole area and processes of manufacturing. In 1979, Crosby published his first business book "Quality Is Free", which became popular at the time because of the crisis in North American quality. During the late 1970s and the 1980s, North American manufacturers were losing market share against Japanese products largely due to the superior quality of the Japanese goods. Crosby's response to the quality crisis was the principle of "doing it right the first time" (DIRFT). He defined four major principles:

1. Quality has to be defined as conformance to requirements, not as goodness (requirements refer to both the product and the customer's requirements);

2. The system for causing quality is prevention, not appraisal. When a defect occurs, discovery and elimination is top priority. Prevention is a knowledge issue for quality-focused workers.

3. The performance standard is zero defects (relative to requirements). Zero defects needs to be a performance standard for everyone in the company, from top management to workers on the line.

The measurement of quality is the price of nonconformance, not indexes.

Cost of quality is also an important communication tool. Crosby demonstrated what a powerful tool it could be to raise awareness of the importance of quality. He referred to the measure as the "price of non-conformance" and argued that organizations choose to pay for poor quality.

Figure 1: Quality-related costs

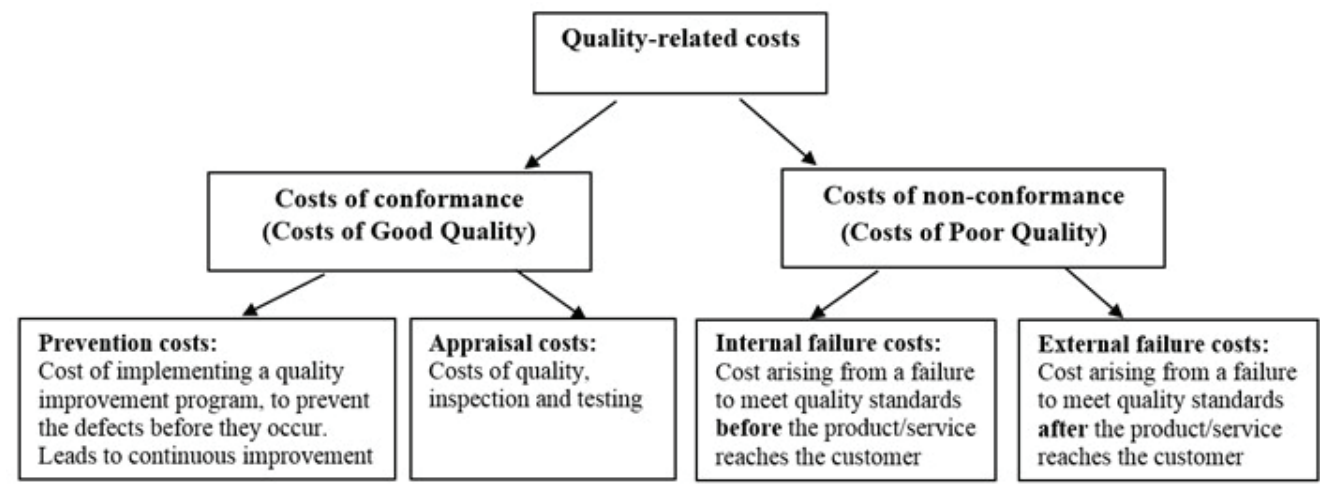

Source: own

Cost of quality is a methodology that allows an organization to determine the extent to which its resources are used for activities that prevent poor quality, that appraise the quality of the organization's products or services, and that result from internal and external failures. Having such information allows an organization to determine the potential savings to be gained by implementing process improvements.

Quality-related activities that incur costs may be divided into prevention costs, appraisal costs, and internal and external failure costs.

Crosby's belief was that an organization, which establishes good quality management principles, would see more savings than they paid for the cost of the quality system, 
which means, "quality is free". It is less expensive to do it in a right way from the beginning than to pay for rework and repairs. For example, in the electronic manufacturing, there was a technological breakthrough in the past decade. The SMT (Surface Mount Technology) became a standard and able to miniaturize the circuits and provide excellent quality even. The environment protection issues such as the Restriction of Hazardous Substances (RoHS) also affected manufacturers, especially who used soldering, that have to introduce lead free soldering. As lead-free and RoHS compliancy fast approaches, it is more important than ever to build it right the first time. Lead-free assembly and RoHS will bring about numerous changes and the number of variables with which to contend is increasing, creating increased risk of defects and reduced product reliability (EU, 2011). Understanding the impacts on the assembly can increase product reliability significantly.

The costs of performing high quality, conducting quality improvements, and achieving goals should be carefully managed so that the long-term effect of quality on the organization is desirable goal. The real value of the quality efforts can be measured by these costs by performing an analysis of the costs of quality. Such an analysis provides a method of assessing the effectiveness of the management of quality and a means of determining problem areas, opportunities, savings, and action priorities.

Traditionally the visible COPQ (Cost of Poor Quality) is representing 4-5\% of the sales and it calls the visible area of the iceberg (Dempsey, 2012)

Figure 2: The cost of quality iceberg

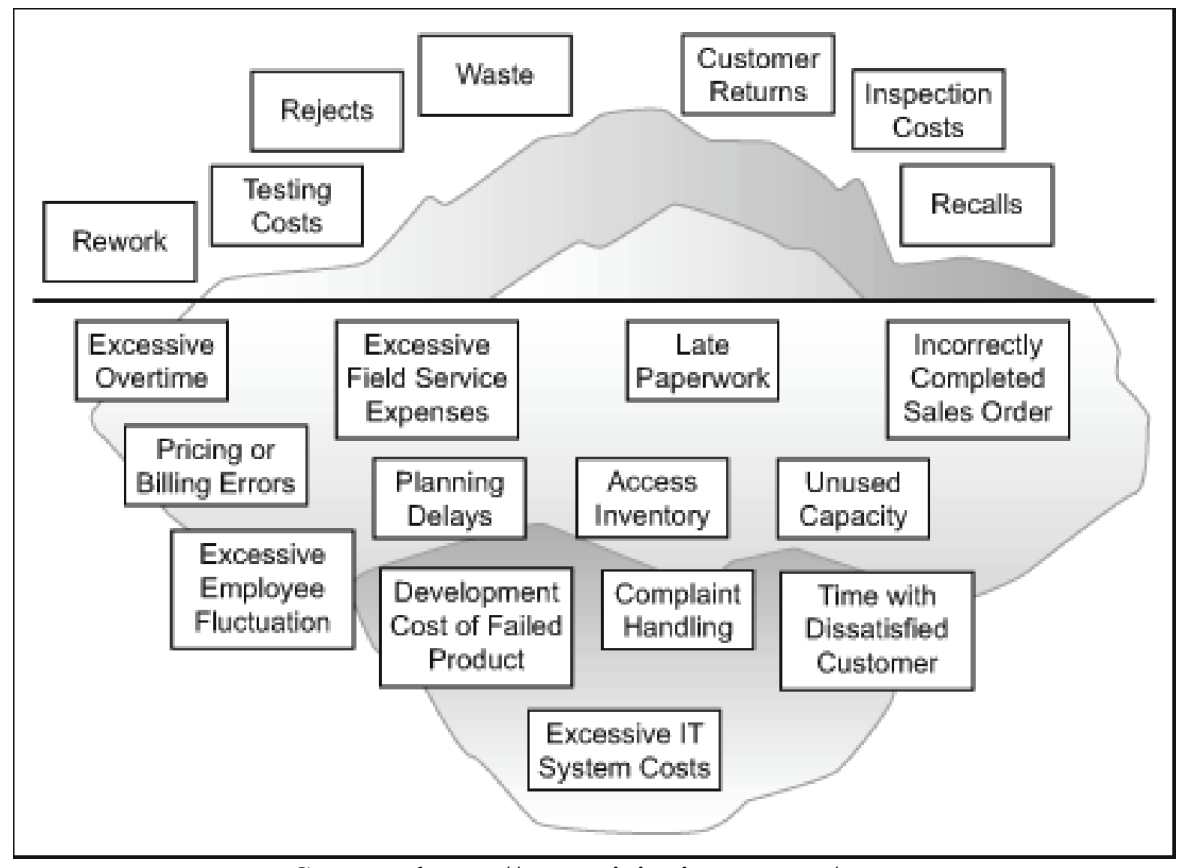

Source: https://www.isixsigma.com/wp-

content/uploads/images/stories/migrated/graphics/767b.gif 
As in case of any iceberg, the hugest and more dangerous part is hidden, as it is beneath the surface of the water and cannot be seen. In general, these "invisible" costs add up to $20-35 \%$ of sales in addition to the "visible" costs. By using COPQ method the company may get a simple and understandable tool for measuring the effects of poor quality and the cost-savings from improvement of the work, and it can be a guidance for top leaders, middle managers and employees as well. Product quality could be a heavy burden if we use the traditional way such as inspection at the end. Quality is coming from the process not from the inspection. Nowadays, due to the automatization and poka-yoke (i.e. mistake proofing) principles the product quality are achievable everywhere.

Many organizations will have true quality-related costs as high as 15 to $20 \%$, sales revenue, sometimes going as high as 40 percent of total operations. A general rule of thumb is that costs of poor quality in a thriving company will be about 10 to 15 percent of operations (Duffy, 2013, pp. 65). Effective quality improvement programs can reduce this substantially, thus making a direct contribution to profits. As Westcott and Duffy (2014) highlighted, the role of managers is crucial in this process, because it will influence the company's performance in the future. The quality cost system, once established, shall be managed in a dynamic way and it will a positive impact on the achievement of the organization's mission, goals, and objectives.

\section{The evolution of quality standards}

The quality standards follow an evolutionary ladder (Rothery, 1997). If we look the ISO 9001:1994 version, it may be seen that it covers the classical quality control requirements. The main requirements are heavy documentation, working based on documented procedures, inspection and permanent product quality.

The next steps are ISO 9001:2000 and 2008 standards (ISO 9001:2000; ISO 9001:2015). These standards introduce the quality objectives, customer satisfaction and process management concept.

The new ISO 9001:2015 standard was released last year. It focuses on the following elements: risk management, use of opportunities, skills (competences) management, and customer satisfaction. It is clearly seen that the new version would like to be a management standard more than before, and wants to eliminate weaknesses of the previous versions such as too much focus on the documentation system or weak risk management. The new ISO focuses on risk management, reduces documentation burden, checks the active participation of the management, performs skill and competence management, and also improves customer satisfaction.

\section{ISO 9001:2015 as a management tool}

The most recent ISO 9001:2015 standard is much more than a standard, it should be the part of a company's strategic plan rather than something to get certified to because it is required. The standard is constructed around seven quality management principles and describes for each part which requirements your products, services and organisation have to meet in order to enjoy the above benefits. The seven principles 
are: customer focus, leadership, engagement of people, process approach, improvement, evidence-based decision making and relationship management (ISO 9000:2015).

To be realized as a management tool, quality principles have to be applied in all operation processes. This concept is realized in the new ISO 9001:2015 standard. The main changes are listed below, which prove that the new ISO 9001 would like to be a "management standard" more than ever.

ISO 9001:2015 has ten clauses instead of eight. The first three clauses are largely similar to the former version, but the new version introduced considerable changes adding seven new clauses, which are arranged according to the PDCA cycle.

Figure 3: Clauses of ISO 9001:2015 in accordance with the PDCA cycle

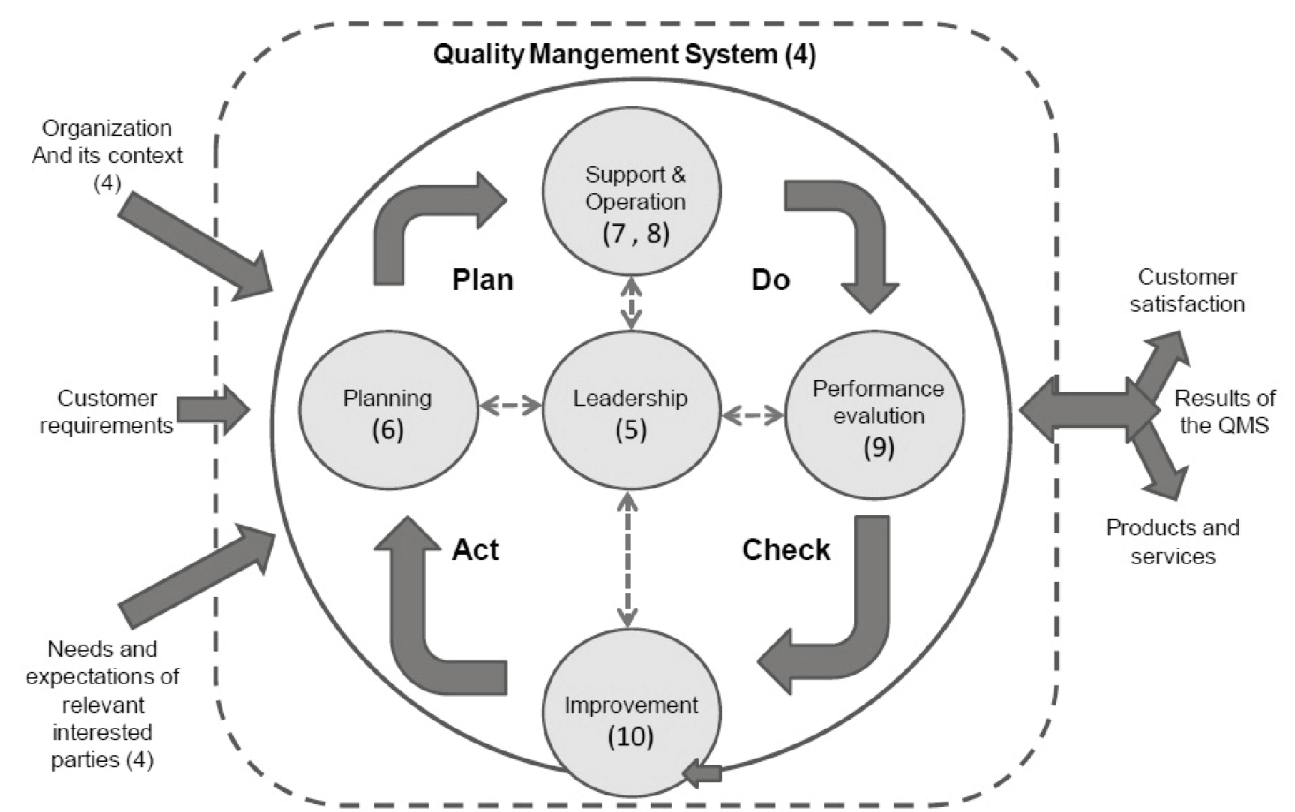

Source: own, based on ISO 9001:2015

Legend: the numbers in brackets refer to the given clause of the new ISO standard

\section{Context of the Organization (Clause 4)}

This is a new concept and relates to the external factors and conditions that affect an organisation (government regulations, sector, competition, technology change etc.). To determine external context, the organisation should consider issues arising from its macroenvironment, i.e. political, social, economic, technological, environmental and legal factors using PESTEL analysis.

The needs and expectations of interested parties (external stakeholders including customers) should also be discussed, as well as internal issues of the organization (shareholders, employees, resources). Internal issues are related to the culture, beliefs, 
values, or principles inside the organization, as well as complexity of processes and organizational structure (Needle, 2004).

Based on the gathered information, a SWOT analysis shall be conducted for combining external and internal issues, which enables the management to define the steps needed for achieving the goals.

\section{Leadership(Clause 5)}

The clause "Management Responsibilities" of ISO 9001:2008 is now addressed in two clauses: "Leadership" and "Planning", it shows clearly that quality management according to the new standard shall strongly rely on the role of leadership, which underlines that quality system should be used as a management tool.

Management is mostly about processes and it relies on tangible measurable capabilities while leadership is mostly about behaviour. Leadership relies on less tangible and less measurable things like trust, inspiration, attitude, decision-making, and personal character. Chapter on Leadership includes three subchapters: 5.1. summarizes general and customer-focused issues of leadership and commitment, 5.2. provides requirements for establishing and communicating quality policy, and 5.3. describes the organizational roles and responsibilities, as well as the relevant authorities. Thus, top management now has greater accountability and involvement in the organization's management system. They shall integrate the requirements of the management system into the organization's core business process in order to ensure that the management system may achieve its intended outcomes and can allocate the necessary resources. Top management is also responsible for communicating the importance of the management system and heighten employee awareness and involvement. (ISO 9001:2015) To be successful, the clear and visible commitment of top management is required and people (employees) should be involved during the whole process. Managers shall lead and manage the change; it is not enough only to support it.

Based on our observations, one of the biggest problem at top management level is the lack of systemic thinking and ensuring the proper allocation of resources is not ideal in most cases. When managers understand this problem, the case cause is won. It should be highlighted that the existence of the efficient management system and the good competence of colleagues will result an effectively working management system, which can highly affect the financial results of the company. Which is encouraging for the future, when top management will adapt quality management system standards they will strive to put more and more emphasis on these requirements. Consequently, we will not talk about hanging certificates just on the wall, but will speak about how a company can manage its risks, so how to avoid losses, damages etc. wherever possible, using the principles of quality management system.

\section{Planning (Clause 6)}

Is a new term introduced to the high level structure, with a requirement to address risks and opportunities and to carefully plan changes within the management system. This new clause brings risk-based thinking to the front. The organization highlighted risks and opportunities in clause 4 , now it needs to define how these will be addressed 
through planning: what actions should be taken to address the risks and opportunities, what are the quality objectives and how to achieve them, and finally, how to plan these changes.

This is an enhanced requirement in the new standard. Risks and opportunities, for example, could relate to the use of electronic systems within the management system. Introducing such systems would require change and transition arrangements, which should be planned within the management system.

\section{Support (Clause 7)}

As a next step, organizations shall define what kind of support is needed to meet their goals and objectives. This includes resources (including infrastructure, environment for the operation of processes, monitoring and measuring resources and organizational knowledge), the targeted communication and documented information that replaces previously used terms such as documents, documentation and records. This new term builds upon the 2008 requirements for competence and awareness, now extended to include persons under the organisation's control, not just employees.

With the increasing use of outsourced providers, this requirement reminds us that this resource must be managed effectively just as internal providers are managed.

\section{Operation (Clause 8)}

The most of the management system requirements are covered by this clause, which is addressed both in-house and outsourced processes. Subchapters deal with operational planning and control, requirements and design of products/services, control of externally provided products/services, production or provision and release of products/services, and control of non-conforming outputs.

\section{Performance evaluation (Clause 9)}

This clause has similar topics to the existing standard, but with a new emphasis on evaluation in addition to the current requirement to measure and analyse.

Evaluation is the interpretation of results and analysis is not new to managers but is made explicit in the standard for the first time. Processes may be well defined and effective, but will they perform optimum results? This may be a new challenge for internal audits.

ISO 9001:2015 is much less prescriptive than previous versions, and incorporates more business management terminology and concepts. Documentation requirements are much less prescriptive and left more to the organisation to judge its own needs. The standard is written for the benefit of organizations. The organization determines what, how and when things are to be monitored, measured, analysed and evaluated adding an internal audit and management review. There are likely to be more challenges to auditors to understand and recognise the extent and type of evidence that would be acceptable to confirm compliance to the 2015 requirements. ISO 9001:2015 auditors will be engaging in dialogue with business leaders, seeking understanding and explanations from them about policy, strategy and quality objectives, and ensuring these are compatible. 


\section{Improvement (Clause 10)}

Improvement has three sub-clauses, in general, it shall discuss product and process improvement and improvement of management practices with a systemic approach. The next step is determination of nonconformities and selecting the corrective actions. The organization must continually improve the suitability, adequacy, and effectiveness of the quality management system, which should be in accordance with the original strategy.

\section{Conclusions and further issues}

Based upon those changes the process approach is more important than ever. The success of the organization is depends on their processes. It is not not enough to develop, produce and sell excellent product, but the organization shall design their business processes to ensure that the realization of product and services, will result the maximum effectiveness, which means the optimal use of the available resources to be met with the customer needs. To improve the business operation and make success, the strategy of the company will help the management if the business processes are considered from the view of process approach.

The concept of modern management places great emphasis on the fact that the company's activities should be smoothly linked together for getting more rapid return on invested capital. Experiences show that it is determined by activities, if they are not linked by function, but are following process approach.

The changes are fasten now, the quick act to the demand of the markets is very important, fast response is the key of success, and companies should be change from reactive approach to proactive.

Business has changed radically since the last major revision of ISO 9001 in 2000; technology has changed our life in many aspects. The Western civilization experienced three industrial revolutions, and now we live in the new, fourth industrial revolution Industry 4.0, when physical objects and machines are connected to an information network and the economy is integrated into a single powerful, intelligent information system.

Europe in the past 20 years lost much of its weight of the industrial production. While in 1991, 36\% of the world's industrial added value was produced in Europe, in 2011, only a quarter. A similar trend has been in Japan and North America, while developing countries have doubled the value-added industrial production.

In the near future, the scale of connected "things" - Internet of Things (IoT), i.e. different inter-networking of physical devices that enable these objects to collect and exchange data. According to Gartner Inc., 6.4 billion connected things will be in use this year and more than 20 billion by 2020 (www.gartner.com). The growth of connected devices and assets has increased concerns about security challenges in IoT. Protecting IoT solutions requires ensuring secure provisioning of devices, secure connectivity between these devices and the cloud, and secure data protection in the cloud during processing and storage. 
Standard organizations should therefore develop and when it is necessary, to adopt these new technologies, reference models, new architectures and open interfaces for IoT. In order to ensure that ISO 9001 continues to serve the business community and maintain its relevance, the standard should be revised and reconsidered continuously, in accordance with the new challenges. One thing remains constant, to be successful, businesses have to adapt to meet the growing needs of customers.

\section{References}

1. Crosby P. (1979): Quality is Free, New York, McGraw-Hill, 270 p.

2. Defeo, J. A.; Juran, J. M. (2014): Juran's Quality Essentials, New York, McGraw-Hill, 280 p.

3. Deming, W. E. (2000): Out of the crisis, MIT-CAES, $510 \mathrm{p}$.

4. Duffy, G. L. (2013): The ASQ Quality Improvement Pocket Guide: Basic History, Concepts, Tools, and Relationships, ASQ Quality Press, pp. 62-65.

5. EU (2011): Directive 2011/65/EU of the European Parliament and of the Council on the restriction of the use of certain hazardous substances in electrical and electronic equipment

6. Feigenbaum, A. V. (2004): Total Quality Control $4^{\text {th }}$ Edition, New York, McGraw-Hill, 896 p.

7. Feigenbaum, A. V. (2009): The Power of Management Innovation: 24 Keys for Accelerating Profitability and Growth, New York, McGraw-Hill, 64 p.

8. IATF (2014): Rules for achieving and maintaining IATF recognition $4^{\text {th }}$ Edition for ISO/TS 16949 , IATF, $16 \mathrm{p}$.

9. Illés, B. Cs., Szuda, Cs. (2015): Quality in manufacturing - is a management tool? In: Dunay, A. (ed.) Proceedings of the 5th International Conference on Management 2015. Management, leadership and strategy for SMEs' competitiveness. Szent István University Publishing House, Gödöllö, pp. 126-129. http://dx.doi.org/10.17626/dBEM.ICoM.P00.2015.p023

10. ISO $9001: 2008$

11. ISO $9001: 2015$

12. Juran, J. M. (1964): Managerial Breakthrough, New York: McGraw-Hill

13. Needle, D. (2004). Business in Context: An Introduction to Business and Its Environment. Thomson Learning, London, $646 \mathrm{p}$.

14. Oakland, J. S. (2014): Total Quality Management, $4^{\text {th }}$ edition, Routledge, $500 \mathrm{p}$.

15. Rothery, B. (1997): ISO 14000 és ISO 9000, Budapest, Panem-McGraw-Hill, 315 p.

16. Taylor, F. W. (1911): The Principles of Scientific Management, Harper \& Brothers

17. Westcott, R. T.; Duffy, G. L. (2014): The Certified Quality Improvement Associate Handbook, Third Edition, ASQ Quality Press, 288. p.

18. http://www.gartner.com/newsroom/id/3165317

19. http://www.isixsigma.com/wp-content/uploads/images/stories/migrated/graphics/767b.gif 